\title{
EDUCAÇÃO AMBIENTAL E REUTILIZAÇÃO DE RESÍDUOS ORGÂNICOS: USO DE COMPOSTAGEM EM UM COLÉGIO DA REDE ESTADUAL DO PARANÁ
}

\author{
ENVIRONMENTAL EDUCATION AND REUSE OF ORGANIC WASTE: THE USE OF \\ COMPOSTING ON A STATE SCHOOL FROM PARANÁ
}

\author{
EDUCACIÓN AMBIENTAL Y REUTILIZACIÓN DE RESIDUOS ORGÁNICOS: USO DE \\ COMPOSTAJE EN UN LICEO DE LA RED ESTATAL DE PARANÁ
}

\author{
Alex Batista Trentin ${ }^{1}$ \\ Paula Raquel Reffatti ${ }^{2}$ \\ Diesse Aparecida de Oliveira Sereia ${ }^{3}$
}

\begin{abstract}
Resumo
O cenário de degradação ambiental torna o futuro do nosso planeta incerto. Diversas organizações tentam reverter este problema e a educação ambiental é um instrumento essencial para uma possível mudança. O objetivo deste trabalho é sensibilizar estudantes do ensino médio sobre a importância do descarte adequado dos resíduos sólidos e demonstrar como é possível mudar atitudes diárias para a preservação ambiental. O projeto foi desenvolvido com alunos do $3^{\circ}$ ano, em um colégio da rede estadual de ensino do Paraná. Em outubro de 2018, produziu-se uma composteira e 13 alunos foram convidados a participar voluntariamente da execução do projeto. Inicialmente, diversas palestras foram realizadas sobre os temas transversais à compostagem. Após a construção, todos os resíduos orgânicos produzidos na escola passaram a ser depositados na composteira. Os alunos foram incentivados, também, a transmitir os conhecimentos adquiridos à comunidade, com o intuito de ampliar a disseminação da educação ambiental. Antes e depois das atividades, aplicaram-se questionários para examinar o conhecimento prévio dos alunos e os saberes desenvolvidos no decurso do projeto. Após as intervenções, visualizou-se, com auxílio dos questionários, a evolução dos alunos, além de uma maior sensibilização em relação à destinação correta dos resíduos gerados. Aspira-se que mais trabalhos sobre o tema sejam realizados no ambiente escolar $-\mathrm{local}$ em que parte da formação dos sujeitos ocorre.
\end{abstract}

Palavras-chave: Biodegradação. Metodologias alternativas. Sensibilização ambiental.

\begin{abstract}
The scenario of environmental degradation makes the future of our planet uncertain. Several organizations are trying to reverse this problem and environmental education is an essential instrument to change the current situation. This work aimed to raise awareness among high school students about the importance of proper disposal of solid waste and demonstrate how simply it is possible to change daily attitudes towards environmental preservation. The project was developed with 3rd grade students from a school in the state education system of Paraná. In October 2018, a composter was produced and 13 students were invited to participate voluntarily of the execution of the project. Initially, several lectures were held on the transversal themes of composting. After construction, all organic waste produced at the school was deposited in the compost bin. The students were also encouraged to transmit the knowledge acquired to the community, aiming to broaden the dissemination of environmental education. Before and after the activities, questionnaires were applied to examine the students' previous knowledge, as well as the knowledge they developed during all the activities. After the interventions, it was possible to visualize, with the help of the questionnaires, the evolution in the students' knowledge about the theme, as well as an awareness about the correct destination of the waste generated. It is hoped that more work aimed at environmental awareness will be carried out in the school environment — where part of the individuals' formation occurs.
\end{abstract}

\footnotetext{
${ }^{1}$ Graduando de Ciências Biológicas - Licenciatura. UTFPR. E-mail: a.trentinx @ gmail.com.

${ }^{2}$ Graduando de Ciências Biológicas - Licenciatura. UTFPR. E-mail: paula_raquelreffatti@ @otmail.com.

${ }^{3}$ Coordenação do curso de Ciências Biológicas - Licenciatura. UTFPR. Doutorado em Biologia Comparada pela Universidade Estadual de Maringá. E-mail: diessesereia@gmail.com.
} 
Educação ambiental e reutilização de resíduos orgânicos: uso de compostagem em um colégio da rede estadual do Paraná

Keywords: Biodegradation. Teaching alternative. Environmental awareness.

\section{Resumen}

El escenario de degradación ambiental vuelve el futuro de nuestro planeta incierto. Diversas organizaciones intentan revertir ese problema y la educación ambiental es un instrumento esencial para un posible cambio. El objetivo de este trabajo es sensibilizar a estudiantes de la educación media sobre la importancia de la eliminación responsable de los residuos sólidos y demostrar cómo es posible cambiar actitudes diarias para la preservación ambiental. El proyecto se desarrolló con estudiantes de tercer año, en un colegio de la red estatal de educación de Paraná. En octubre de 2018 se construyó una compostera y 13 alumnos fueron invitados a participar de forma voluntaria en la ejecución del proyecto. Inicialmente, se realizaron varias charlas sobre temas transversales al compostaje. Después de la construcción, todos los desechos orgánicos producidos en la escuela pasaron a ser depositados en la compostera. Los alumnos fueron incentivados, también, a trasmitir los conocimientos adquiridos a la comunidad, con el propósito de ampliar la difusión de la educación ambiental. Antes y después de las actividades, se aplicaron cuestionarios para examinar el conocimiento previo de los alumnos y los desarrollados en el curso del proyecto. Después de las prácticas, se pudo comprobar, por medio de cuestionarios, el progreso de los alumnos, además de una gran sensibilización respecto a la eliminación correcta de los residuos generados. Se espera que más trabajos sobre el tema sean desarrollados en el ambiente escolar —_ lugar en donde se produce parte de la formación de los sujetos.

Palabras-clave: Biodegradación. Metodologías alternativas. Sensibilización ambiental.

\section{Introdução}

Com o desenvolvimento da sociedade, o grande crescimento industrial e a ascensão do capitalismo, inúmeros problemas ambientais surgiram — em diversos aspectos da biosfera. Impactos ambientais envolvem, além dos fatores físicos e bióticos, como o ar, a água e o solo, questões antropológicas; ou seja, a sociedade depende do ambiente onde vive. Torna-se necessário, portanto, o surgimento de políticas e programas que coloquem o homem como responsável pelos seus atos em tópicos ambientais (ANDRADE; PINTO, 2017; PEREIRA, et al., 2017).

Surge, então, a nível global, o grande desafio de promover um estilo de vida baseado no Desenvolvimento Sustentável (DS); somente a partir de uma formação voltada para as questões ambientais, será possível promover mudanças comportamentais nos indivíduos, pois, ao adquirir as competências essenciais necessárias, podem difundir o DS (JERONEN; JERONEN; RAUSTIA, 2008).

A geração extrema de resíduos urbanos cria a necessidade diretamente proporcional de políticas educacionais voltadas à sustentabilidade, em relação ao crescimento e desenvolvimento da sociedade moderna (CÓRDULA; NASCIMENTO, 2012; MAIA; AZEVEDO; ARAÚJO, 2018).

A educação ambiental é necessária para que a nova geração tenha a consciência e os conhecimentos necessários para que se tenha um melhor cuidado com as condições do planeta. Utilizando-se da nova forma de ensino e aprendizagem, torna-se mais simples desenvolver a 
educação ambiental, com atividades criativas e que incentivem o pensamento crítico, bem como uma paixão maior sobre o assunto. Jacobi (2003) fala sobre a educação ambiental como uma forma de desenvolver a presença da comunidade nas decisões e nas fiscalizações, em relação ao progresso socioambiental.

Os resíduos sólidos urbanos (RSU) são agravantes da degradação ambiental; estima-se que 50\% de toda a produção de RSU no Brasil sejam de resíduos orgânicos, porém eles são descartados inadequadamente (FIGUEIREDO, et al., 2019). Uma alternativa para a gestão correta desses resíduos é a compostagem; este é um processo natural, capaz de degradar a matéria orgânica, resultando em um fertilizante passível de utilização em diversos aspectos (SIQUEIRA; ABREU, 2016).

Conforme Costa et al. (2015), a compostagem, mesmo sendo uma técnica antiga, tem se desenvolvido muito em políticas de gestão ambiental, visto que este processo natural permite uma melhor gestão dos resíduos orgânicos, revertendo em um produto com diversas aplicações.

A formação humana, sistematizada, ocorre no ambiente escolar, onde os conteúdos são organizados em forma de currículos; assim, inserir neste entorno a sensibilização humana, acerca de questões sociais, pode contribuir para uma formação humana integral e uma sociedade culturalmente mais evoluída na questão ambiental.

Neste contexto, este trabalho objetivou sensibilizar estudantes do ensino médio de um colégio da rede pública sobre a importância do descarte adequado dos resíduos sólidos, através do uso de metodologias alternativas de ensino; além disso, demonstrou-se como, de forma simples, é possível mudar atitudes diárias voltadas para a preservação ambiental.

\subsection{A necessidade da Educação Ambiental no Ensino Básico}

A partir da década de 90, a Educação Ambiental passa a ser regulamentada pela Lei $\mathrm{n}^{\circ}$ 9.795/1999, que institui a Política Nacional de Educação Ambiental (PNEA) como componente essencial e permanente da educação nacional, devendo estar presente, de forma articulada, em todos os níveis e modalidades do processo educativo (BRASIL, 1999).

A crise ambiental global traz à tona a necessidade de sociedades mais conscientes no que se trata de sustentabilidade, sendo assim, um dos melhores momentos para iniciar-se a inserção deste conhecimento é na educação básica, afinal, é neste momento em que os jovens aprimoram seus conhecimentos. Desta forma, a educação ambiental, inserida pela lei 9.795, de 27 de abril de 1999, é um tema transversal, que pode ser desenvolvido em diferentes anos do ensino básico (CÂMARA et al., 2018). 
O estudo sobre o meio ambiente, e os problemas contidos nesse contexto, tornam os estudantes mais articulados ao assunto, bem como com maior visibilidade social do planeta e do ambiente onde vivem (JACOBI, 2003). Com o tema sendo abordado, permite-se que os alunos tenham embasamento sobre os problemas e catástrofes ambientais que ocorrem e possam vir a ocorrer (CARVALHO; REIS, 2017).

Como recordado por Santos (2007), a constituição federal brasileira prevê, em seu parágrafo $1^{\circ}$ do art. 255, que o governo deve promover a educação ambiental na educação fundamental, média e superior. Entretanto, é preciso aprimorar a prática docente, para fomentar saberes e consciência sobre os assuntos ambientais. Cuba (2010) relata, também, a falta de infraestrutura dos centros de ensino para a educação ambiental.

As escolas que consigam formar indivíduos conscientes sobre desenvolvimento sustentável devem ser utilizadas como modelo por outras instituições de ensino. Muitas escolas e docentes têm buscado estratégias diferenciadas, com vistas à implantação da EA no cotidiano escolar (RODRIGUES; FARRAPEIRA, 2008; SILVA; LEITE, 2008; SOUZA, et al., 2013; ALVES; FILHO, 2020). Contudo, não existe uma escola que possa ser considerada modelo a ser seguido, visto que cada ambiente escolar possui suas peculiaridades, diferenças e necessidades; é necessário considerar aspectos da região, além do contexto social e cultural onde a escola está inserida. Assim, os profissionais da educação e a comunidade escolar devem buscar estratégias que promovam a EA em todas as formas de ensino, com o propósito de sensibilizar os estudantes e a sociedade sobre sua responsabilidade ética com o ambiente (FISCHER, 2017). No que lhe concerne, o governo deve, além de financiar a educação ambiental, verificar e monitorar sua eficiência.

\subsection{Coleta Seletiva e Reciclagem}

Conforme Ribeiro e Lima (2000), os recursos naturais mundiais estão se tornando escassos de forma exponencial, em função do tempo. Além disso, deve-se considerar que a sociedade descarta seus resíduos inadequadamente no ambiente; logo, a necessidade de reciclagem é uma prática essencial. A reciclagem é o processo de reaproveitamento e reutilização de certas categorias de resíduos, porém, para que este processo possa ocorrer, o lixo precisa ser separado. Segundo o Compromisso Empresarial para Reciclagem (Cempre), a partir de um estudo realizado em 2016, cerca de apenas 18\% das cidades brasileiras possuem coleta seletiva; portanto, há uma necessidade de iniciativas particulares para realizar este processo, com o intuito de mitigar os impactos ao meio ambiente. 
A Política Nacional de Resíduos Sólidos (PNRS), instituída pela Lei 12.305, almeja a preservação dos recursos naturais, a partir da redução de resíduos gerados. Impõe-se ao indivíduo a responsabilidade de descartar corretamente e realizar a separação correta dos resíduos; a lei engloba, também, o poder público e vários outros setores produtivos (BRASIL, 2010).

Bringhenti (2004) aponta que se o lixo reciclável tiver um mesmo fim que outros resíduos, ele pode perder seu potencial e qualidade - causado pela contaminação por materiais orgânicos e/ou inorgânicos. Assim, a coleta seletiva é fulcral para a preservação do meio ambiente porque, além da reciclagem e reutilização de materiais, contribui para a criação de matéria orgânica utilizável como adubo, por meio da compostagem e biodegradação.

O descarte incorreto do lixo pode causar inúmeras perdas ambientais, pois diversos resíduos que poderiam ser reutilizados são simplesmente descartados. Além disso, Azevedo (1996) aponta que este descarte incorreto provoca a contaminação do ar, solo e águas, devido a possíveis agentes poluidores oriundos dos resíduos. Neste contexto, a escola se torna importante agente para a coleta seletiva, pois pode incentivar a prática da separação correta do lixo pela comunidade escolar — devido à grande quantidade de resíduo que produz. Felix (2007) aponta que o trabalho escolar ambiental é importante, pois pode aprimorar a conduta ambiental dos jovens em desenvolvimento.

\subsection{Compostagem}

A compostagem é um processo biológico que conta com a ação de microrganismos para a biodegradação de materiais orgânicos. Hamerschmidt e Oliveira (2014) apontam que a compostagem se baseia na degradação, a partir de um procedimento que pode ocorrer com ou sem a presença de oxigênio, em um sistema com variações de energia. A metodologia da compostagem acontece com a liberação de $\mathrm{CO} 2$ e vapor d'água; produz-se, assim, um tipo de adubo abundante em matéria orgânica, perfeito para fertilização de hortas e jardins.

A partir deste processo, é possível reduzir a emissão de gás metano que, atualmente, está muito presente na atmosfera terrestre, o que contribui para a propagação do efeito estufa. Além de ser um processo ecologicamente correto e, com grande benefício para o meio ambiente, a compostagem é uma excelente ferramenta para desenvolver a educação ambiental no âmbito escolar. Conforme Souza et al. (2013), o aprendizado ambiental ocorre de forma mais significativa quando se desenvolve a partir de técnicas práticas, auxiliando os alunos a aprimorarem seu pensamento crítico em relação aos fatores socioambientais. 


\section{Material e métodos}

O trabalho, aqui relatado, faz parte das atividades executadas pelo Programa Institucional de Iniciação à Docência (PIBID), vinculado à Universidade Tecnológica Federal do Paraná, Brasil. O presente estudo foi realizado em um colégio estadual do Paraná, no município de Dois Vizinhos; a investigação ocorreu em outubro de 2018, em uma turma de $3^{\circ}$ ano do ensino médio - que contava com 13 alunos matriculados. A pesquisa ocorreu em duas partes; inicialmente, trabalhou-se, em sala, questões relacionadas à gestão e destinação correta dos RSU e, posteriormente, aplicaram-se questionários com o propósito de observar os conhecimentos prévios dos estudantes sobre os conteúdos de coleta seletiva, meio ambiente, biodegradação e compostagem.

Após a aplicação dos questionários, o trabalho focou na educação ambiental. Realizaram-se rodas de conversa com os alunos, com explicações sobre o conceito de meio ambiente, melhores formas de realizar o descarte dos RSU; além disso, abordou-se como a produção e o funcionamento do processo da compostagem e biodegradação acontece.

Após as conversas em sala de aula, os alunos foram dirigidos ao local onde seria produzida a composteira; informações gerais sobre ela foram compartilhadas e sua produção iniciada. Assim, a composteira foi desenvolvida no campus do colégio, com a ajuda dos alunos.

A composteira foi desenvolvida em um espaço reservado no campus, a qual ocorreu, inicialmente, na produção de um buraco na terra com dimensões de $1 \mathrm{~m}$ de comprimento $\mathrm{x} 70$ $\mathrm{cm}$ de largura x $50 \mathrm{~cm}$ de profundidade. Em seguida, esta base foi preenchida com folhas secas e folhas ainda verdes, com vistas ao controle da temperatura e da umidade na compostagem (Figura 1).

Figura 1: A) Fase inicial da montagem da composteira, folhas para controle da umidade. B) Composteira

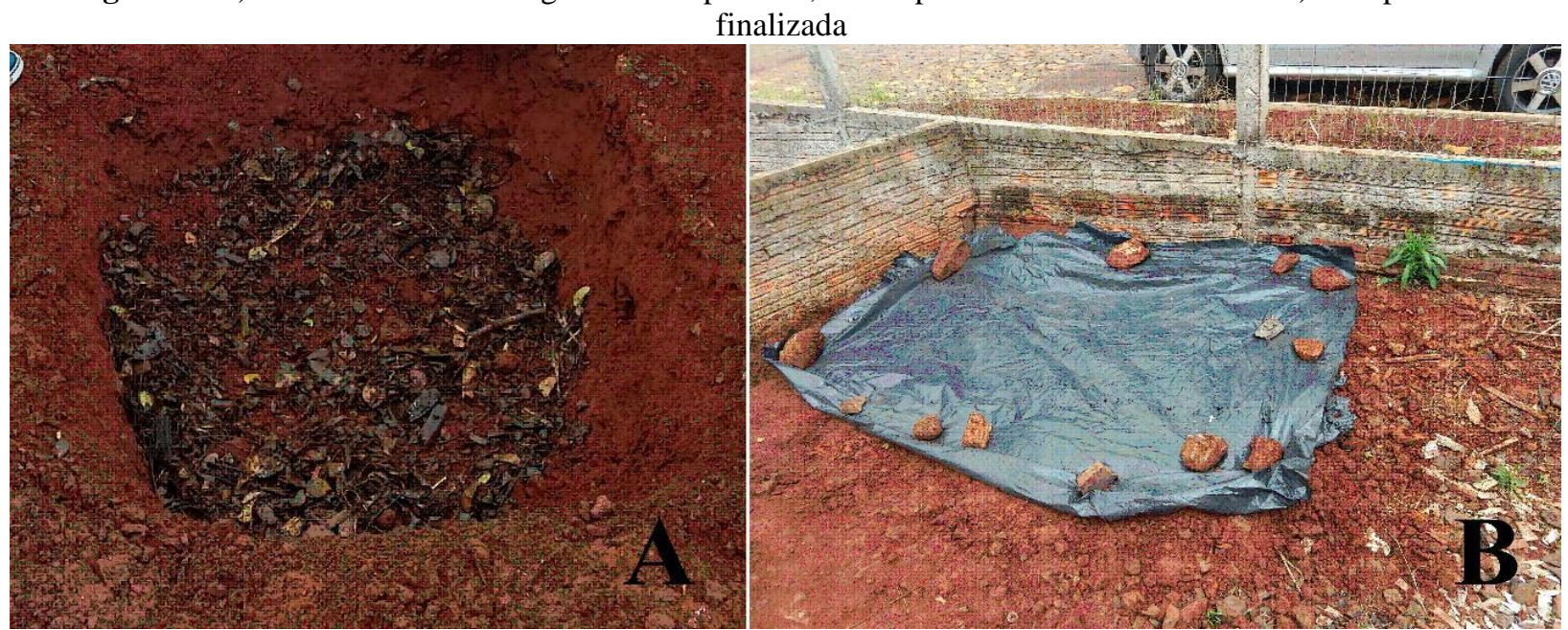

Fonte: acervo dos autores (2018). 
Realizaram-se reuniões com toda a equipe escolar para que houvesse uma maior sensibilização para com o descarte correto dos resíduos; solicitou-se, também, que todo o resíduo orgânico coletado na escola fosse descartado na composteira, mantendo assim o abastecimento da mesma.

Por fim, os mesmos questionários foram aplicados novamente, com o propósito de verificar o conhecimento adquirido pelos alunos durante as rodas de conversa e produção da composteira no colégio.

\section{Resultados e discussões}

Dos 13 alunos matriculados, somente 10 alunos estavam presentes (77\%) no dia da aplicação do projeto; a turma era composta majoritariamente por meninas $(70 \%)$ e minoritariamente por meninos (30\%), com idades que variavam entre 14 e 19 anos.

As primeiras perguntas do questionário eram diretamente aplicadas à disposição correta de RSU. Em relação à destinação correta dos resíduos, observou-se que $60 \%$ dos alunos não costumavam realizar a separação do lixo em suas casas; já no questionário pós aplicação das atividades, este percentual diminuiu para em torno de 20\%. Quanto à segunda questão, visualizou-se uma pequena diferença em relação às categorias de separação, conforme figura 2.

Figura 2: Categorias de separação pré e pós aplicação das atividades

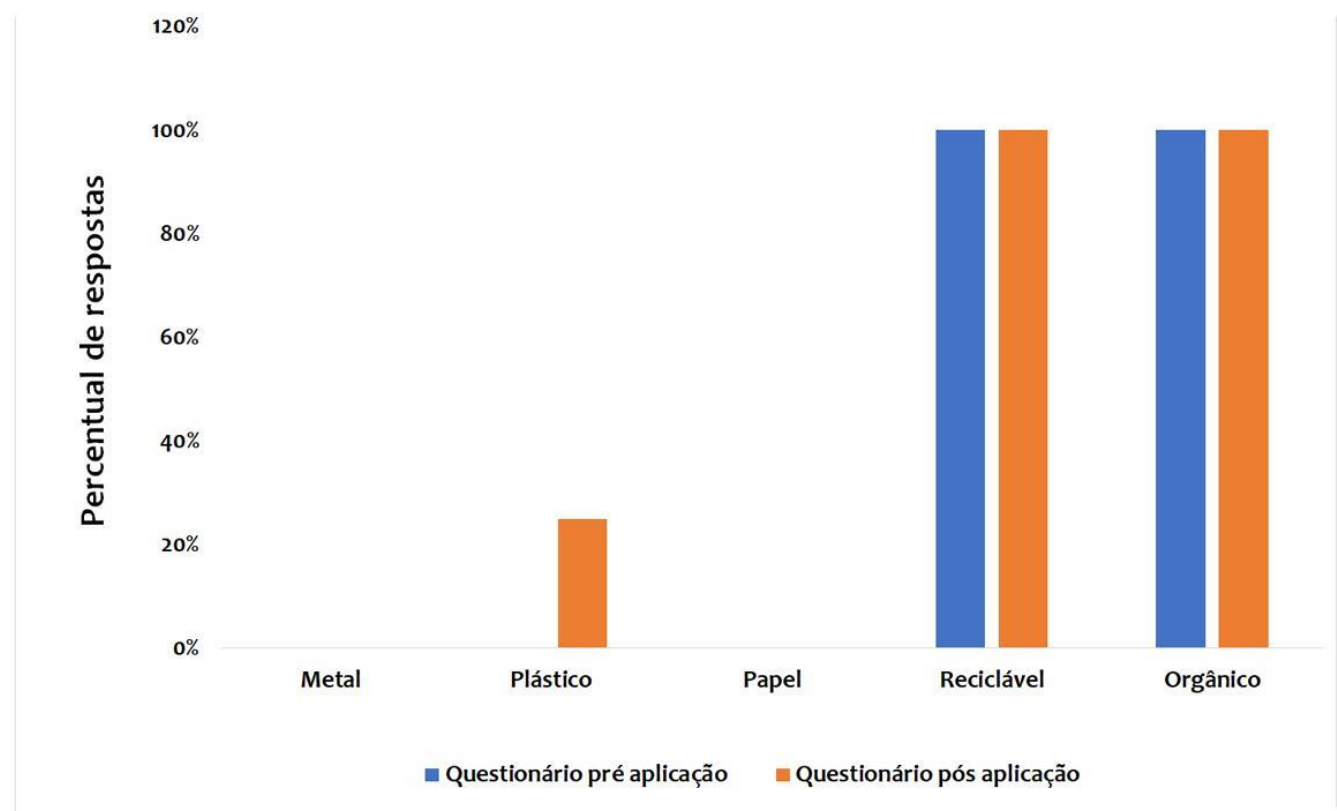

Fonte: acervo dos autores (2018)

Tratando-se dos conhecimentos sobre descarte dos resíduos, houve certa disparidade nas respostas dos alunos quanto aos resíduos orgânicos. Aproximadamente $40 \%$ afirmou não 
descartar a borra do café no lixo orgânico, o que demonstra uma falta de conhecimento sobre a diferença entre produtos orgânicos e não orgânicos. Após a aplicação das atividades, essa dúvida desapareceu, com $100 \%$ das respostas corretas, afirmando que somente as categorias: papel, baterias e garrafas PET não deveriam ser destinadas ao lixo orgânico. Corrobora-se, assim, com as ideias de Cuba (2010) que descreve a necessidade de um maior programa de incentivo à educação ambiental nos colégios brasileiros, sendo necessário assim, mais infraestrutura nos institutos de ensino básico do país.

Os estudantes demonstraram diversas dúvidas quando questionados sobre biodegradação e compostagem, a partir dos questionários aplicados. Em relação à questão que tratava sobre os organismos que auxiliavam na biodegradação, a opção "minhocas" obteve maior taxa de resposta, cerca de $60 \%$, enquanto fungos e bactérias obtiveram, respectivamente, $40 \%$ e $20 \%$ das respostas obtidas. Os vermes, mesmo sendo auxiliares no processo de compostagem de resíduos orgânicos, não são os protagonistas, pois fungos, bactérias e outros microrganismos são os principais causadores da biodegradação (Teixeira et al., 2002). A figura 3 apresenta os dados dos questionários pré e pós atividades, onde, após as palestras realizadas, os alunos conseguiram compreender o papel dos microrganismos na biodegradação.

Por fim, a última questão sobre o conteúdo abordou os motivos que tornam a compostagem algo útil, principalmente no ambiente escolar, o que, conforme Wangen (2010), torna-se útil por conta do seu baixo custo, utilização do produto final como fertilizante e uma forma de dar um destino aos resíduos orgânicos, sendo assim, prevenindo o mau cheiro e animais vetores de doenças. O questionário apresentou 3 opções de vantagens da compostagem, onde todas estavam corretas, sendo que, inicialmente, $90 \%$ dos alunos responderam que a única vantagem da compostagem era a produção de adubo orgânico, enquanto $10 \%$ não responderam à questão. Para o questionário pós, 100\% responderam como correta as 3 questões apresentadas (Figura 3). 
Figuras 3: A) Organismos que auxiliam na biodegradação. B) Vantagens da compostagem: Diminuição de mau cheiro nas lixeiras (A), produção de adubo orgânico (B) e prevenção de animais vetores de doenças (C).
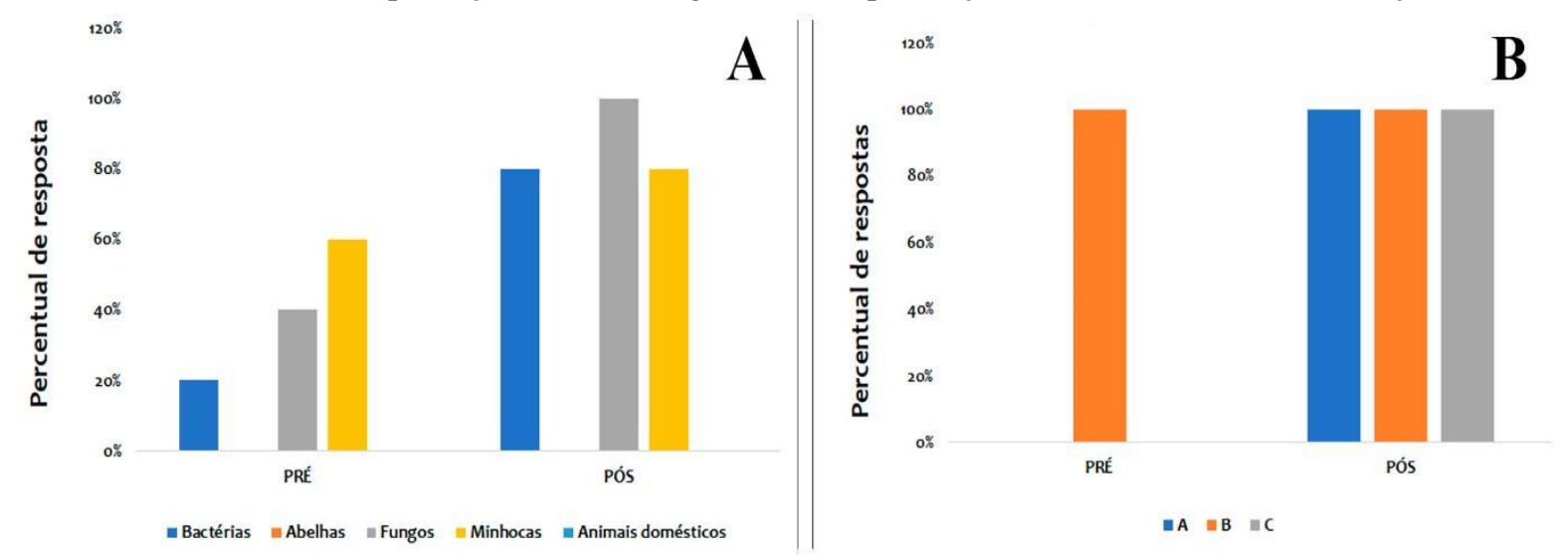

Fonte: acervo dos autores (2018)

Como finalização dos questionários, os alunos foram convidados a apresentar sua opinião dos alunos sobre a criação de uma composteira no ambiente escolar; no primeiro questionário as respostas ficaram divididas, $40 \%$ afirmaram achar necessário a compostagem, $30 \%$ disseram não ser fundamental a presença e 30\% não responderam à questão. Em contrapartida, no segundo momento, $100 \%$ dos alunos afirmou considerar útil a presença de uma composteira no campus escolar. Essa diferença, nas respostas entre questionário pré e pós, é considerada pela falta de conhecimento dos alunos, no âmbito da compostagem e biodegradação.

\subsection{Produção de composteira escolar}

Durante o processo de produção da composteira na escola, observou-se um grande entusiasmo por parte dos discentes do $3^{\circ}$ ano ensino médio que, na maioria das disciplinas são considerados uma turma desmotivada. As aulas práticas tendem a motivar e despertar a atenção dos estudantes. Lima e Garcia (2011), apontam as vantagens da utilização de aulas práticas, pois são instrumentos inovadores que reforçam a concentração dos alunos, tornando assim o processo de ensino-aprendizagem mais prazeroso; além disso, a abordagem faz com que o aluno consiga guardar as informações e aprender de forma mais fácil e rápida.

A execução da composteira ocorreu com o auxílio dos alunos e permitiu uma maior interação no quesito teórico-prático; possibilitou-se, assim, uma fixação maior dos conhecimentos, visto que, enquanto eram realizadas conversas sobre a aplicação e vantagens de uma composteira, ela estava sendo produzida.

Após a realização da composteira e as conversas com toda a equipe da escola, incluindo corpo docente e pedagógico, parte administrativa e operacional, o processo foi colocado em 
prática. A equipe de limpeza e da cozinha cumpriu o papel de alimentar semanalmente a composteira com os resíduos orgânicos oriundos da escola, pois com sobras de alimentos provenientes da cozinha e dos horários de alimentação dos alunos é possível um abastecimento contínuo da composteira; a partir destes resíduos, o desenvolvimento de um produto rico em nutrientes pode ocorrer (SANTOS, 2014). Assim, depois de 3 semanas, o processo de biodegradação dos compostos orgânicos se iniciou, conforme figura 4.

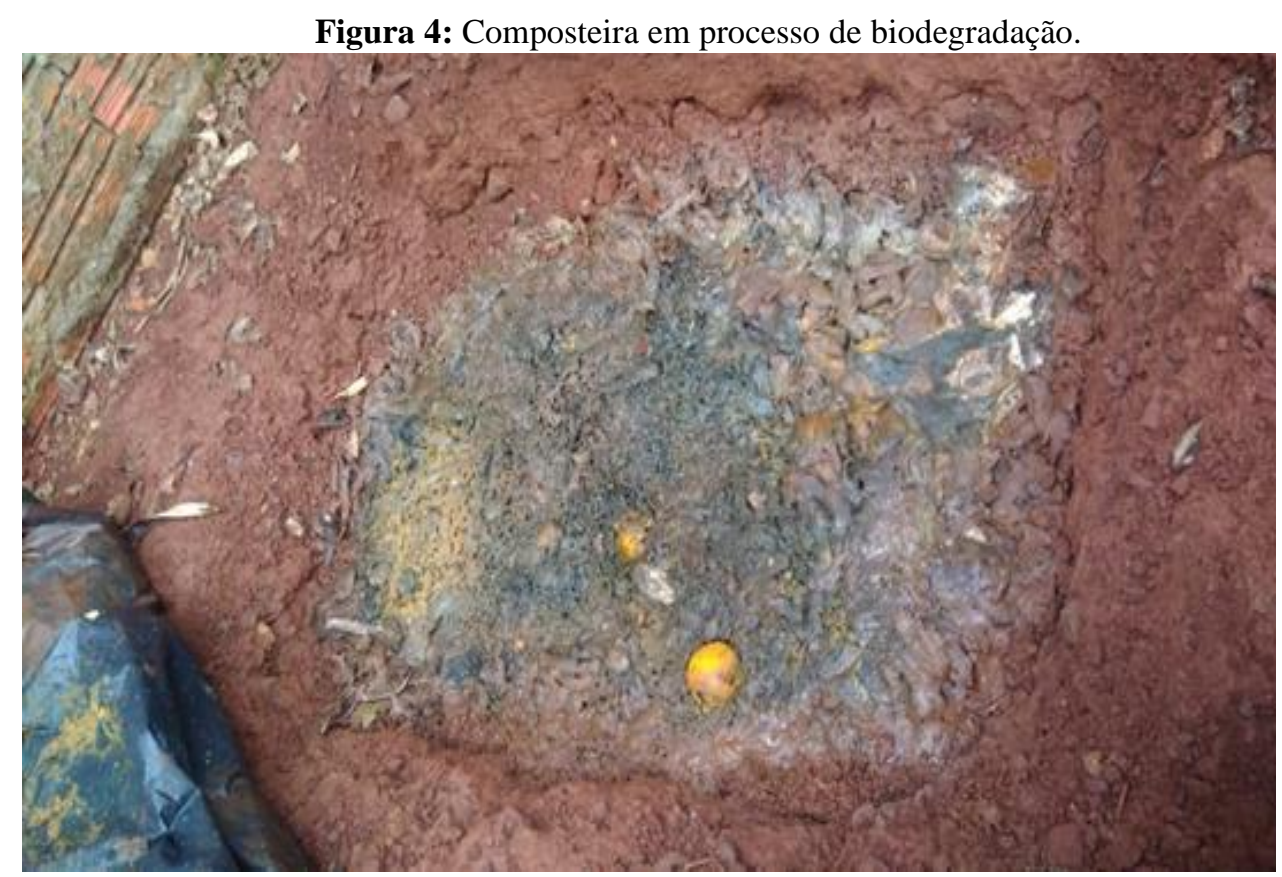

Fonte: acervo dos autores (2018)

\section{Considerações finais}

Com o crescimento dos problemas do meio ambiente, a educação ambiental é indispensável na atualidade, pois os jovens devem estar preparados para mitigar os efeitos dessa degradação no futuro. Discute-se o descarte correto do lixo seco para sua reciclagem e reutilização, porém os resíduos orgânicos são de extrema importância para o meio ambiente; logo, formas de descarte e reutilização destes resíduos também devem ser incentivadas. A compostagem é uma ótima forma de realizar a reciclagem dos resíduos orgânicos, por ser um processo de baixo custo e possível de ser realizado em diversos ambientes; ainda, é capaz de produzir um adubo fértil e adequado para utilização em hortas e jardins.

O ambiente escolar, por conter diversos indivíduos, produz diariamente grandes quantidades de resíduos orgânicos que, por meio da compostagem, podem ser reutilizados; a partir dela, também é possível educar os alunos sobre o meio ambiente e preservação. $O$ presente trabalho, a partir da aplicação de questionários iniciais, demonstrou que falta um maior 
aprofundamento nos temas ambientais dentro das escolas brasileiras, pois, a partir das atividades realizadas, verificou-se um aumento significativo no conhecimento e na sensibilização dos alunos.

A partir das rodas de conversa, os alunos foram incentivados a realizarem corretamente o descarte de seus RSU, bem como a transmitir estas informações a toda sua comunidade. Com a produção da composteira, criou-se uma forma fácil, barata e ecológica de dispor os resíduos produzidos na escola, além de auxiliar a explicação dos conteúdos para os alunos.

É importante frisar que todas as espécies que habitam o globo necessitam de um habitat com qualidade e sustentabilidade. Neste caso, é urgente que, sistematicamente, as escolas desenvolvam uma formação com ênfase na educação ambiental. Espera-se que mais trabalhos voltados para a sensibilização ambiental sejam executados no ambiente escolar. Com a composteira instalada, almeja-se que os docentes continuem a desenvolver mais atividades deste tipo, na escola alvo da pesquisa.

\section{Agradecimentos}

Ao Programa Institucional de Iniciação à Docência - PIBID vinculado à Coordenação de Aperfeiçoamento de Pessoal de Nível Superior (CAPES); e a Universidade Tecnológica Federal do Paraná -UTFPR.

\section{Referências}

ALVES, K. L.; FILHO, R. E. F. Observação de aves e Educação Ambiental: percepções de alunos de escola pública, Uberlândia/MG. Revista Turydes: Turismo y Desarrollo Local Sostenible, [s.l], v. 13, n. 28, p. 349-361, jun. 2020.

ANDRADE, L. B.; PINTO, V. P. S. Os Riscos, a Vulnerabilidade Ambiental e o Estado Capitalista: a proposta de uma Educação Ambiental como ato político. REMEA - Revista Eletrônica do Mestrado em Educação Ambiental, [s.l.], v. 34, n. 3, p. 207-225, dez. 2017.

AZEVEDO, C. J. C. Concepção e prática da população em relação ao lixo domiciliar na área central da cidade de Uruguaiana- RS. 19996. 68f. Monografia (Pós-graduação em Educação ambiental) - PUCRS, Uruguaiana, 1996.

BRASIL. Ministério do Meio Ambiente. Lei n. 9.795/1999. Dispõe sobre a educação ambiental, institui a Política Nacional de Educação Ambiental e dá outras providências. Brasília: Presidência da República, Casa Civil, 1999.

BRASIL. Lei $\mathbf{n}^{\mathbf{0}}$ 12.305, de 2 de agosto de 2010. Regulamento Institui a Política Nacional de Resíduos Sólidos; altera a Lei no 9.605, de 12 de fevereiro de 1998; e dá outras providências. Brasília: Presidência da República, Casa Civil, 2010. 
BRINGHENTI, J. Coleta seletiva de resíduos sólidos urbanos: Aspectos operacionais e da participação da população. 2004. Tese (Doutorado em saúde ambiental) - USP, São Paulo, 2004.

CÂMARA, A. C. et al. Referencial de Educação Ambiental para a Sustentabilidade para a Educação Pré-Escolar, o Ensino Básico e o Ensino Secundário. Brasília: Ministério da educação, 2018.

CARVALHO, V. A. O.; REIS, É. V. B. A necessidade da releitura da ação educativa presente na educação ambiental como pré-requisito ao alcance do meio ambiente ecologicamente equilibrado. Revista de Pesquisa e Educação Jurídica, Brasília, v. 13, n. 1. p. 22-43. 2017.

COLETA seletiva. CEMPRE, [20-]. Disponível em: http://cempre.org.br/ciclosoft/id/8. Acesso em: 19 jul. 2019.

CÓRDULA, E. B. de L. A HERMENÊUTICA DA EDUCAÇÃO AMBIENTAL E O PARADOXO DA SUSTENTABILIDADE. Revista Eletrônica em Gestão, Educação e Tecnologia Ambiental, [s.1.], v. 8, n. 8, p.1573-1580, 9 jan. 2013.

COSTA, A. R. S. et al. O processo da compostagem e seu potencial na reciclagem de resíduos orgânicos. Revista GEAMA, Recife, v.1, n.2, p. 246-260. Set, 2015.

CUBA, M. A. Educação ambiental nas escolas. ECCOM, [s.l.], v. 1, n. 2, p. 23-31, jul./dez., 2010.

DIAS, L. S.; LEAL, A. C.; JUNIOR, S. C. Educação ambiental: Conceitos, metodologias e práticas. São Paulo: ANAP 2016.

FIGUEIREDO, R. T.; BRITO, M. J. C.; SANTOS, P. H. C.; SOARES, C. M. F.; BURLE, E. C. MONITORAMENTO DE COMPOSTAGEM EM PEQUENA ESCALA. Semioses, [s.l.], v. 13, n. 3, p.98-107, set. 2019.

FISCHER, M. L.; et al. Da ética ambiental à bioética ambiental: antecedentes, trajetórias e perspectivas. Hist. cienc. Saúde, Rio de Janeiro, v. 24, n. 2, abr.jun. 2017.

FELIX, R. A. Z. Coleta Seletiva em Ambiente Escolar. Revista Eletrônica do Mestrado em Educação Ambiental, Rio Grande do Sul, v. 18, p. 56-71, 2007.

HAMERSCHIMIDT, I.; OLIVEIRA, S. Alimentação saudável e sustentabilidade ambiental nas escolas do Paraná. Curitiba: Instituto Emater, 2014.

JACOBI, P. Educação ambiental, cidadania e sustentabilidade. Cadernos de Pesquisa, n. 118, p. 189-205, mar. 2003.

LIMA, D. B.; GARCIA, R. N. Uma investigação sobre a importância das aulas práticas de Biologia no Ensino Médio. Cadernos do Aplicação, Porto Alegre, v. 24, n. 1, jan./jun. 2011.

MACEDO, M. A. A. P. T; RAMOS, M. C. P. Educação Ambiental e Resíduos Sólidos Urbanos: Caminho para um Futuro Sustentável. EDUSER, Revista de educação, Bragança, v. 7, n. 2. 2015. 
MAIA, A. L. A.; AZEVEDO, E. B.; ARAÚJO, N. M. S. A questão ambiental nocapitalismo: o destino dos resíduos sólidos na gestão pública do meio ambiente. Revista Libertas, Juiz de Fora, v. 18, n. 2, p. 19-32, ago. /dez. 2018.

PEREIRA, R. S. et al. O discurso da sustentabilidade no capitalismo: uma falácia? In: ENCONTRO INTERNACIONAL SOBRE GESTÃO EMPRESARIAL E MEIO AMBIENTE, 19., 2017, São Paulo. Anais [...]. São Paulo: USP, 2017.

RODRIGUES, L. L.; FARRAPEIRA, C. M. R. Percepção e Educação Ambiental sobre o ecossistema manguezal incrementando as disciplinas de Ciências e Biologia em escola pública do Recife-PE. Investigações em Ensino de Ciências, Porto Alegre, v. 13, n.1, p.7993, 2008.

RIBEIRO, T. F.; LIMA, S. C. Coleta seletiva de lixo domiciliar: estudos de casos. Caminhos de Geografia, [s.l.], v. 1, n. 2, p. $50-69,2000$.

SANTOS, A. M. L. et al. Incentivo ao Uso da Compostagem de Resíduos Sólidos em uma Horta Escolar do Município de Jaciara-MT. UNOPAR Cient., Ciênc. Human. Educ., Londrina, v. 15, n. esp., p. 321-329, dez. 2014.

SANTOS, E. M.; FARIA, L. C. M. O educador e o olhar antropológico. Fórum Crítico da Educação: Revista do ISEP/Programa de Mestrado em Ciências Pedagógicas, [s.l.], v. 3, n. 1 , out. 2004.

SILVA, M. M. P.; LEITE, V. D. Estratégias para realização de Educação Ambiental em escolas do ensino fundamental. Rev. Eletrônica do Mestrado em Educação Ambiental, Rio Grande, v. 20, jan./jun. 2008.

SIQUEIRA, T. M. O.; ABREU, M. J. Fechando o ciclo dos resíduos orgânicos: compostagem inserida na vida urbana. Ciência e Cultura, [s.l.], v. 68, n. 4, p. 38-43, dez. 2016.

SOUZA, A. C. A Experimentação no Ensino de Ciências: importância das aulas práticas no processo de ensino aprendizagem. Monografia (Especialização em Educação) - UTFPR, Medianeira, 2013.

SOUZA, G. S; et al. Educação ambiental como ferramenta para o manejo de resíduos sólidos no cotidiano escolar. RevBEA, [s.l], v. 8, n. 2, 118-130, 2013.

TEIXEIRA, R. F. F. Compostagem. In: HAMMES, V. S. (org.). Educação ambiental para o desenvolvimento sustentável. Brasília: Embrapa Informação Tecnológica, 2002.

WANGEN, D. R. B.; FREITAS, I. C. V. Compostagem doméstica: alternativa de aproveitamento de resíduos sólidos orgânicos. Revista Brasileira de Agroecologia, [s.l.], v. 5, n. 2, nov. 2010. ISSN 1980-9735. Disponível em: http://revistas.abaagroecologia.org.br/index.php/rbagroecologia/article/view/7601. Acesso em: 19 jul. 2019. 